\title{
Turbulent transport of discharged ground water in oceanic bottom boundary layers in a water channel experiment
}

\author{
Nils Karow ${ }^{1}$, Leonie Kandler ${ }^{1}$, Martin Brede ${ }^{1}$, Sven Grundmann ${ }^{1}$ \\ ${ }^{1}$ Faculty of mechanical Engineering, Chair of Fluid Mechanics, University of Rostock, Rostock, 18059, Germany \\ 5 Correspondence to: Nils Karow (nils.karow@uni-rostock.de)
}

\begin{abstract}
.
In the context of the DFG research training Group Baltic Transcoast the scalar transport of discharged submarine groundwater and the included tracer substances are investigated. The research focus is the mixing of ground water under the

10 influence of waves in shallow coastal water. The waves are generated by a Piston type wave generator and can be varied with respect to the specific wave parameters. In the water channel a permeable sea bed model is installed which allows the intrusion of a florescent tracer fluid into the measurement area. The transport of this tracer in the water column is affected by the wave motion and is analysed using optical measurement technology. The methods used are on the one hand the Particle Image Velocimetry, to determine the velocity field in the measurement area. On the other hand, simultaneous Laser Induced

15 Florescence is used to obtain the concentration field. Thus, the relation between the unsteady velocity field and the mixing of the tracer can be determined quantitatively.
\end{abstract}

\section{Introduction}

The Baltic Sea is one of the biggest brackish water seas on earth. Its nutrient balance, salinity and oxygen level is influenced by many factors. These factors are responsible for the growth, the survival and the development of the marine flora and

20 fauna in the Baltic sea, especially in the coastal zones.

While the inflow of salty water from the North Sea is effectively known (Matthäus and Franck, 1992), the influence of submarine groundwater discharge (SGD) is not completely understood. (Burnett et al., 2006), (Leote et al., 2008), (Moore, 2010), (Burnett et al., 2001), (Robinson et al., 2007)) mentioned SGD as a significant source of nutrients for the Baltic sea. These nutrients play an important role in the change of the environmental behavior in coastal zones. The changes and

25 influences of such a nutrient transport are investigated in a number of studies. This shows that the entrance of nutrients in the seas is highly dependent on SGD.

The (IOC et al., 2004 // 1984) emphasized the importance of the SGD for the environment and recommend the research need in this area. 
https://doi.org/10.5194/os-2019-116

Preprint. Discussion started: 2 January 2020

(c) Author(s) 2020. CC BY 4.0 License.

(c) (1)

(Leote et al., 2008), (Taniguchi et al., 2006), (Ullman et al., 2003) and (Finkl and Krupa, 2003) present local area studies in which the SGD flux and nutrient transport are estimated. While the importance of nutrients is discussed in several studies and reviews and the flux itself is under investigation, it is evident, that another important part of the water cycle is the transport and mixing in the water column itself. (Feddersen, 2012) noted that wave action will influence the periodic 5 movement of the bottom boundary layer significantly.

This bottom boundary layer has various definitions in different specific fields. In fluid mechanics the bottom boundary layer is defined as the $99 \%$ line of speed of the mean flow velocity (Schlichting, 1954). In ocean science this bottom boundary layer is introduced as the benthic boundary layer (Boudreau and Jørgensen, 2001). This layer is defined as "that part of the marine environment that is directly influenced by the presence of the interface between the bed and its overlying water"

10 (Boudreau and Jørgensen, 2001).

The mixing and transport processes in this zone and the interaction with the permeable seabed are not completely understood. (Huettel et al., 1996) investigate the development of the oxygen level in the upper permeable seabed. He used a constant flow field in a water channel above a rippled bed which was dyed with Rhodamine as a tracer for the oxygen level. (Precht and Huettel, 2003) determined how waves influence dye transport within a permeable seabed by using a small wave 15 channel with a rippled seabed which was dyed with Rhodamine, similar to the experiments of (Huettel et al., 1996).

To understand the general transport mechanism above the permeable seabed into the water column, the following experiment was established. 


\section{Basics}

\subsection{Field Study Site - NSG Heiligensee Hüttelmoor}

The nature reserve Heiligensee Hüttelmoor is located north-east of Rostock at the coast of the Baltic Sea in northern Germany. This area is a characteristic landscape of the southern Baltic Sea coastline. It is a coastal wetland and due to the

5 typical regional hydrological structuring, exchange processes between the fen and the Baltic Sea are common. Since 1975 the Hüttelmoor is a nature reserve. Due to the geographical location and the proximity to the Baltic sea, the region is affected by exchange processes with the Baltic sea. (Miegel et al., 2016) describe specific area information in detail. The seaside of the nature reserve is subject to typical wave conditions for this region of the Baltic Sea. To determine the specific wave conditions for our location an Acoustic Wave And Current - Profiler (AWAC) was installed. The position and a map of the

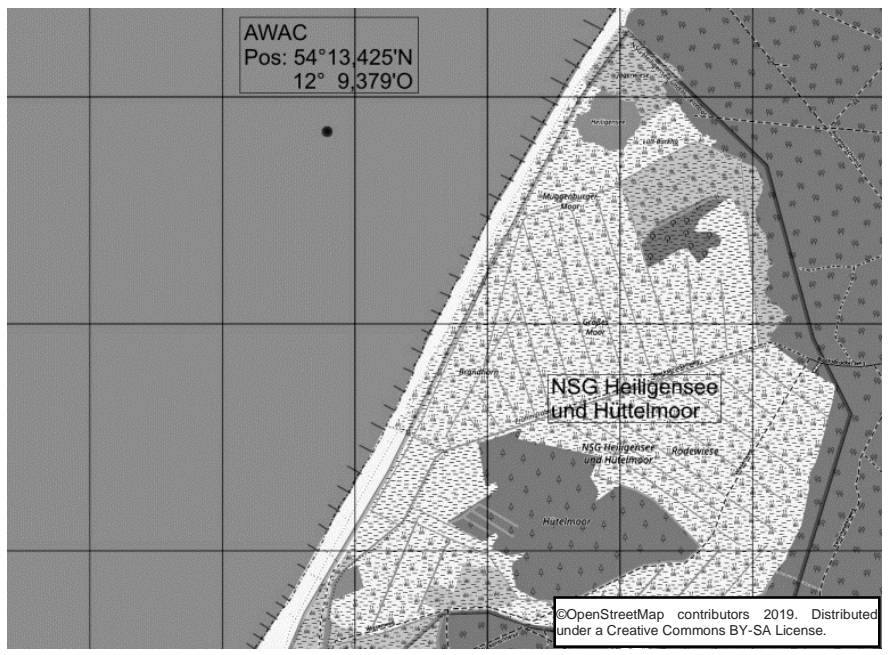
field study site are shown in Figure 1. The measurement system is placed in $1 \mathrm{~km}$ distance from the coastline. At a water depth of 4 to $5 \mathrm{~m}$ the ground is sandy, but the movement of the bed load is low in this area, thus the burial of the system is negligible. The measurements provide field data over a period of one year. These datasets are used to determine the wave conditions in the laboratory wave channel experiment. The AWAC system delivers specific wave characteristics like the wave speed, the wave height and the wave period. Other parameters are calculated using stochastic and analytic wave theory.

\section{Figure 1: field study site and position of the AWAC}

The field study site is located in the north-east of Germany near the city of Rostock. The black point within the figure shows the position of the AWAC. The measurement system is placed in a water depth between 4 and $5 \mathrm{~m}$. 


\subsection{Submarine Groundwater Discharge (SGD)}

Submarine groundwater discharge is a general term for every kind of submarine groundwater flowing through the seabed into the water column. (Moore, 2010) defines SGD as follows: "includes any and all flow of water on continental margins from the seabed to the coastal ocean, with scale lengths of meters to kilometers regardless of fluid composition or driving

5 force". This is the most common definition of SGD. It distinguishes between two classes of SGD. The terrestrial freshwater SGD is defined as the Submarine Groundwater which has its origin on the landside, due to precipitation and the groundwater level itself. The other type is the seawater recirculation SGD: This class is the most common one and is the biggest part of the SGD flux. (Robinson et al., 2007) add two more classes (see Figure 2). The SGD rate is controlled by several physical processes. On the one hand are the land-derived drivers like hydrological processes, the ground properties (e.g. permeability), recharge through rainfall and the structure and developments of rivers on the land side.

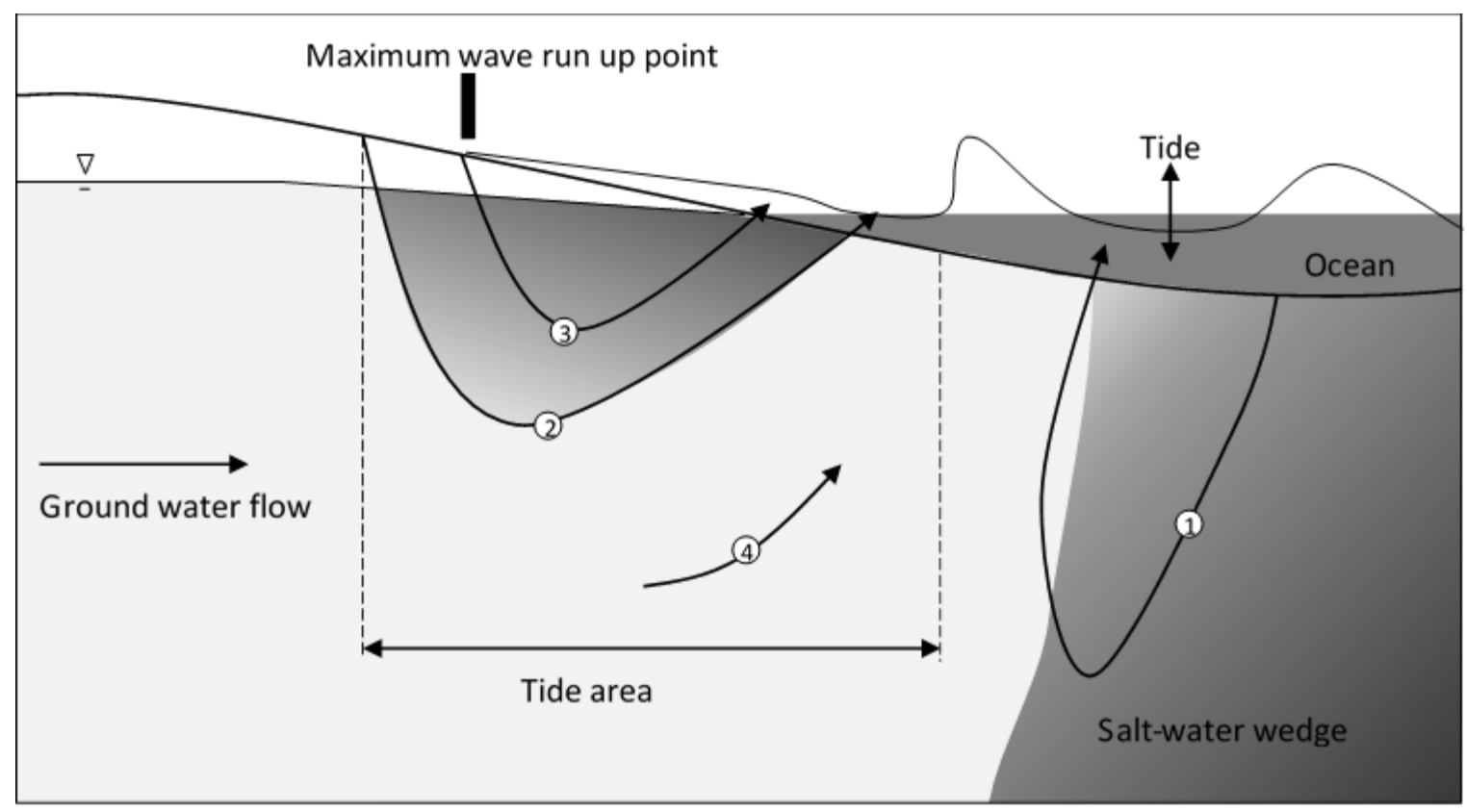

Figure 2: Types of Submarine Groundwater Discharge after (Robinson et al., 2007)

The types of the Submarine Groundwater Discharge are divided into 1) recirculating ocean water, 2) a flux of drained rainwater from the dunes, 3) recirculated water from the uprunning waves and 4) the direct Groundwater flow.

On the other hand, marine induced drivers are important: Due to water level fluctuations, tidal amplitudes and wave action the hydraulic gradient changes significantly over time. As (Moore, 2010) points out, in most cases (nearly 95\%) the discharges consist of saline recirculated seawater. 


\subsection{Wave theory}

The scaling and the analysis of the experiment are based on boundary conditions, which have to be derived from theoretical aspects. Therefore, the wave theory is a core aspect of the following result and discussion section. Because of the water depth and the ordinary wave conditions in this area of the Baltic sea, the required wave theories for the physical circumstances are the linear wave theory of (Airy, 1845) and the third order Stokes theory (Stokes, 2009). Ocean surface waves are categorized into three types.

$\begin{array}{ccc}\begin{array}{c}\text { deep water } \\ \text { zone }\end{array} & \begin{array}{c}\text { intermediate water } \\ \text { zone }\end{array} & \begin{array}{c}\text { shallow water } \\ \text { zone }\end{array} \\ \mathrm{h} / \mathrm{L}>0.5 & 0.05<\mathrm{h} / \mathrm{L}<0.5 & \mathrm{~h} / \mathrm{L}<0.05\end{array}$

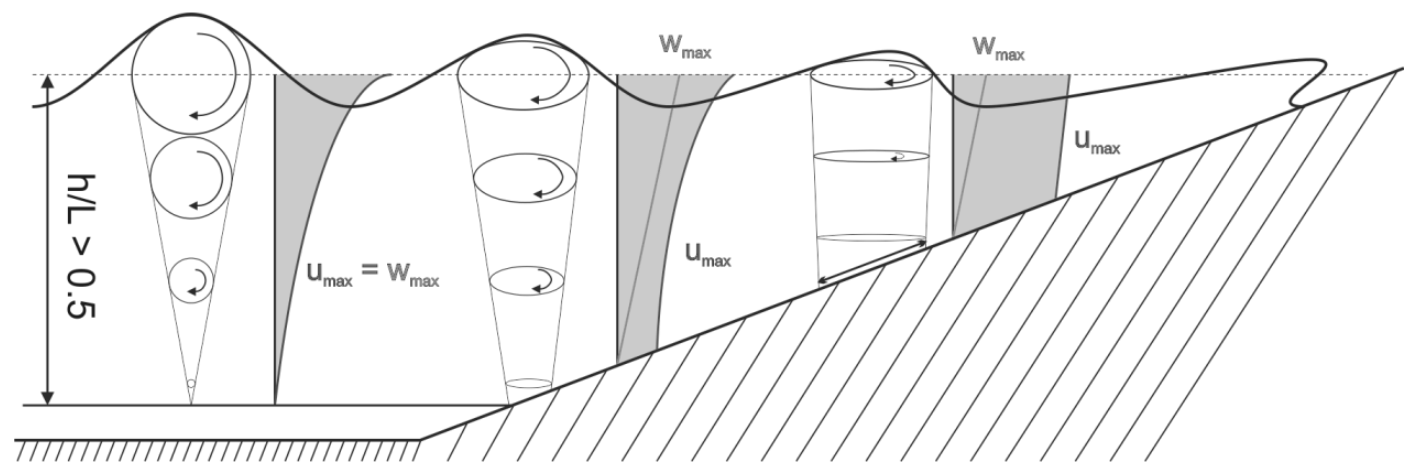

Figure 3: ocean surface wave types

In the categorization of ocean waves 3 zones are defined, the deep water zone, the intermediate water zone and the shallow water zone. The classification is based on the ratio of the water depth to the wavelength.

The classification is based on the ratio of the water depth and the wavelength. According to this definition deep-water waves begin to occur at a ratio of 0.5 . They exhibit a nearly circular orbital path. The maximum horizontal and the maximum

15 vertical velocity component are equal. Furthermore, the water movement will end in the water column and will not reach the bed. In shallower areas, the movement of the water particles changes. Shallow-water waves are distinguished by an elliptic orbital path. Thus, the maximum of the horizontal velocity component is much greater than the vertical one. This leads to a nearly horizontal movement of the water particles over the seabed. In between these well-defined wave regimes, the socalled intermediate wave region appears.

20 The study area is placed in the intermediate zone. Thus, the following equations of the third order Stokes wave theories are chosen for this region. According to (Ausschuß für Küstenschutzwerke, 2002) the wave speed becomes

$$
c=\sqrt{\frac{g}{k} \tanh (k h) \cdot\left[1+k^{2} a^{2} \frac{8+\cosh (4 k h)}{8 \sinh ^{4}(k h)}\right]}
$$


$\mathrm{k}$ is defined as the wavenumber, $\mathrm{g}$ as the gravity acceleration, a as amplitude and $\mathrm{h}$ as the water depth. Furthermore, the orbital velocity is given by the following equations:

$$
\begin{aligned}
u_{\theta} & =c \cdot\left[k \cdot a \cdot \frac{\cosh [k(z+h)]}{\sinh (k h)}\right] \cos (\theta)+\frac{3}{4} k^{2} a^{2} \cdot \frac{\cosh [2 k(z+h)]}{\sinh ^{4}(k h)} \cos (2 \theta) \\
& +\frac{3}{64} k^{3} a^{3} \cdot \frac{11-2 \cosh (k h)}{\sinh ^{7}(k h)} \cosh [3 k(z+h)] \cdot \cos (3 \theta) \\
w_{\theta} & =c \cdot\left[k \cdot a \cdot \frac{\sinh [k(z+h)]}{\sinh (k h)}\right] \sin (\theta)+\frac{3}{4} k^{2} a^{2} \cdot \frac{\sinh [2 k(z+h)]}{\sinh ^{4}(k h)} \sin (2 \theta) \\
& +\frac{3}{64} k^{3} a^{3} \cdot \frac{11-2 \cosh (k h)}{\sinh ^{7}(k h)} \cdot \sinh [3 k(z+h)] \cdot \sinh (3 \theta)
\end{aligned}
$$

With $\theta$ as the phase angle and $\mathrm{z}$ as axis orthogonal to the water surface, the wavelength can be assumed as follows:

$$
\lambda=\frac{g}{\omega} T \cdot \tanh (k h) \cdot\left[1+k^{2} a^{2} \frac{14+4 \cosh ^{2}(2 k h)}{16 \sinh ^{4}(k h)}\right]=c \cdot T
$$

The wavenumber $\mathrm{k}$ and the angular frequency $\omega$ are defined by:

$$
\begin{aligned}
& k=\frac{2 \pi}{\lambda} \\
& \omega=\frac{2 \pi}{T}
\end{aligned}
$$

With these equations all wave parameters can be determined by measuring the wave amplitude, wave speed and the wave period.

\section{$10 \quad 2.4 \quad$ Turbulent Kinetic Energy}

The turbulent kinetic energy shows the averaged turbulent velocity fluctuation in the flow in all directions. It is produced by friction between the fluid and the ground or by fluid shear itself. The energy in the 2D case is calculated with the following equation:

$$
T K E=\frac{1}{2}\left(\overline{\left(u^{\prime}\right)^{2}}+\left(\overline{\left(w^{\prime}\right)^{2}}\right)\right)
$$


https://doi.org/10.5194/os-2019-116

Preprint. Discussion started: 2 January 2020

(c) Author(s) 2020. CC BY 4.0 License.

\subsection{PLIF - Planar Laser Induced Fluorescence and Particle Image Velocimetry}

The PLIF measurement technique combines a particle image velocimetry (PIV) system and a laser induced fluorescence (LIF) system in a one-plane laser light sheet setup. The separate measurement methods use the same laser light sheet as the measurement area. This light sheet is optically captured using two Dantec Flowsense 2M CCD cameras. In Figure 4 the combined setup is shown.

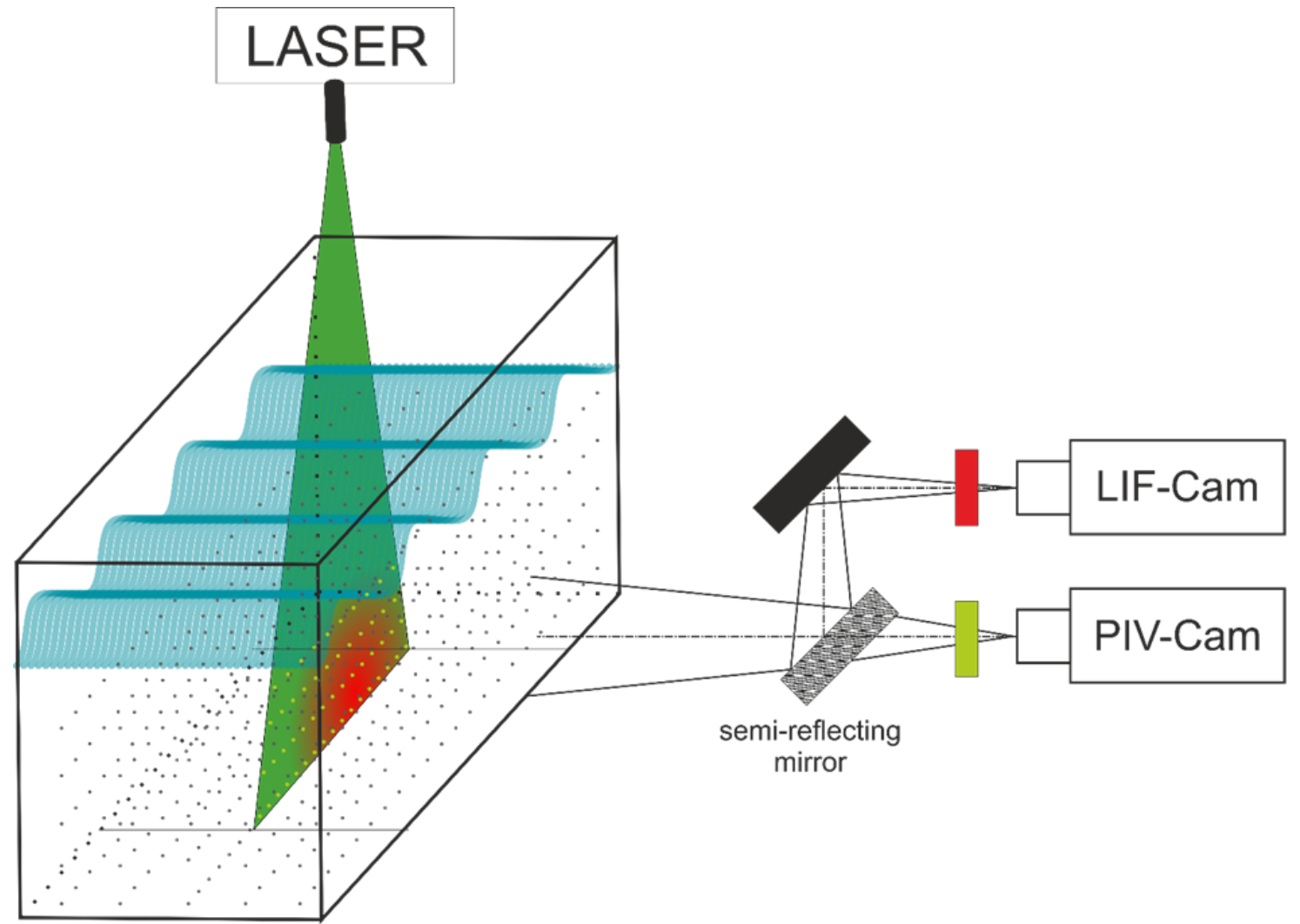

Figure 4: PLIF measurement technique

On the left side a flow channel with reflecting particles (small points) and a fluorescent fluid (red colour) is shown. Furthermore, a Laser light sheet is reflected on the particles and activate the fluorescent fluid. On the right the two camera setups are coupled with a semi-reflecting mirror, thus both cameras capture the same image simultaneously.

Since both cameras capture the same picture, it possible to combine the results in the post processing. An optical bandpass filter is installed in front of the LIF-camera to remove the light reflected by the PIV-particles. The PIV setup captures double images to calculate the velocity field with a correlation-based algorithm. In the LIF setup, a fluorescence tracer (Rhodamine $6 \mathrm{G})$ in the infused ground water is used to investigate the concentration field. 
https://doi.org/10.5194/os-2019-116

Preprint. Discussion started: 2 January 2020

\section{Materials and Methods}

\subsection{Water Channel}

The experiment is placed in a water channel at the Chair of Fluid Mechanics at the University of Rostock. The channel is $5 \mathrm{~m}$ in length, $0.8 \mathrm{~m}$ in width and $1 \mathrm{~m}$ high. For the wave generation, a Piston type wave generator is installed which can excite

5 waves of defined height, period and speed. The generator moves a flat plate as piston using a linear axis with a servo engine. To suppress backscatter of the waves, a wave absorber is placed at the end of the channel. This absorber is built of a stack of plates of increasing height perpendicular to the wave motion resulting in a nearly complete absorption of the backscatter.

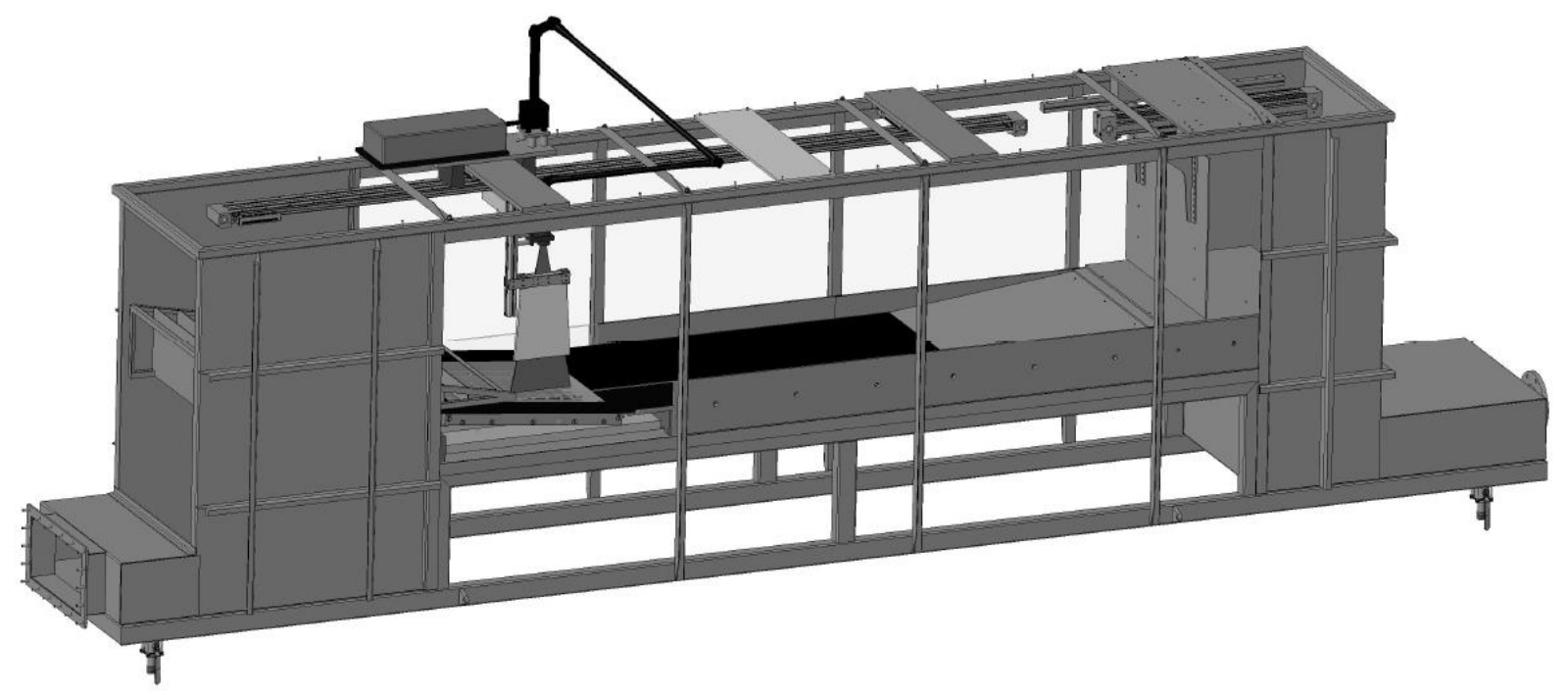

10 Figure 5: CAD Model of the Water Channel

In the model, a ground plate system is shown with an adjustable case for different porous media. On the right side a Piston type wave generator is installed and on the left side an absorber system.

The measurement area is located in front of the absorber system. A special ground plate system was developed to realise a groundwater discharge within this area. It consists of a reservoir with a size of $570 \mathrm{~mm} \times 480 \mathrm{~mm} \times 5 \mathrm{~mm}$ defining the framed base for a changeable seabed model of a size of $690 \mathrm{~mm}$ x $600 \mathrm{~mm}$ x $60 \mathrm{~mm}$. In between, a distribution plate with different openings can be placed to realise a consistent discharge (see Figure 6). An entrance for tracer fluid is placed at the bottom of the reservoir. Above this entrance a special divider is installed to divide the inflow and damp the momentum of the tracer fluid (see Figure 7). The whole ground plate system can be changed in its angular position. Thus, the slope angle of the 20 seabed model is changeable. 
https://doi.org/10.5194/os-2019-116

Preprint. Discussion started: 2 January 2020

(c) Author(s) 2020. CC BY 4.0 License.

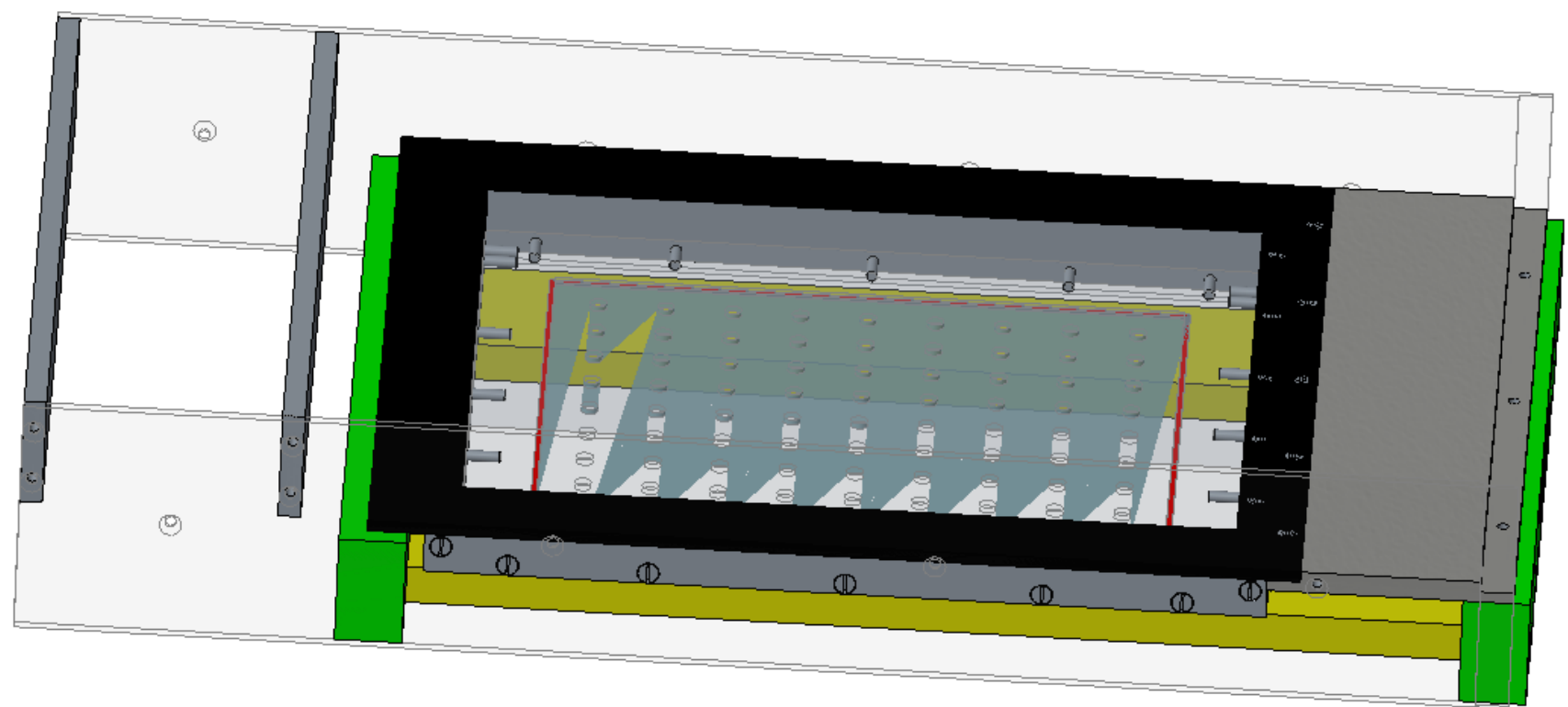

Figure 6: Reservoir and distribution plate

In the ground plate model, this reservoir is placed underneath the measurement area. In this framed base, the seabed model is placed with a size of $690 \mathrm{~mm} \times 600 \mathrm{~mm} \times 60 \mathrm{~mm}$. At the bottom of this reservoir, the Tracer entrance is placed.

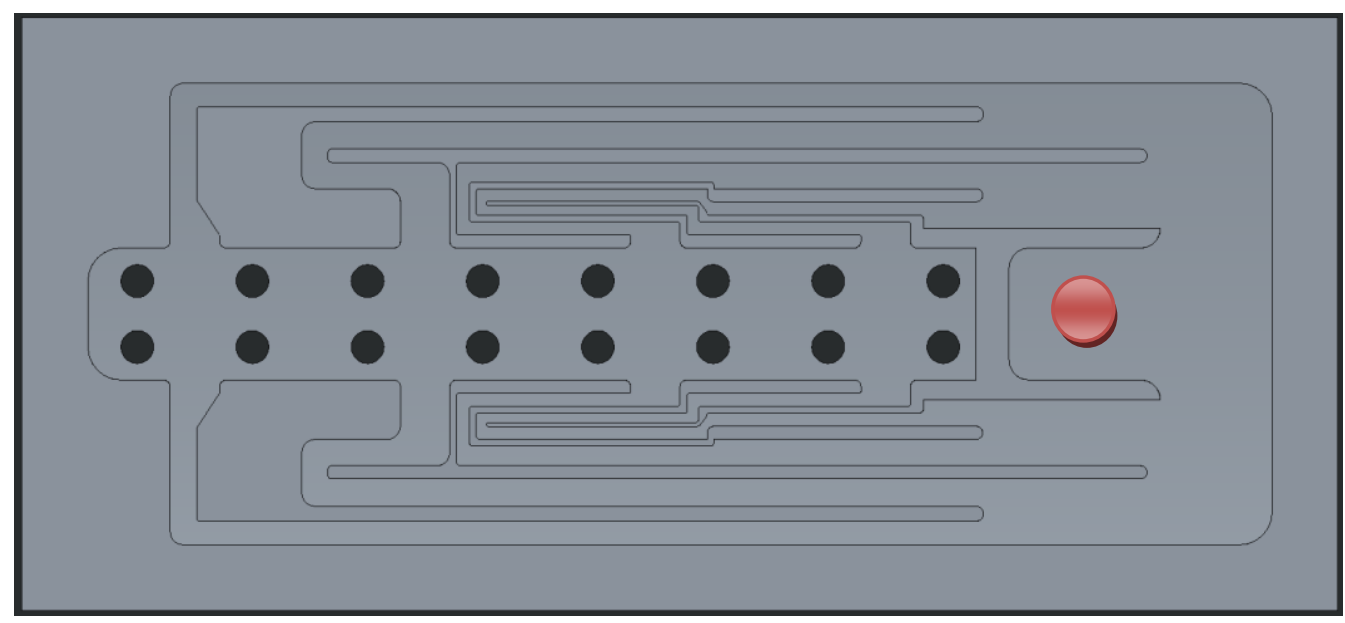

Figure 7: Divider above the Tracer entrance

The divider is placed directly above the entrance of the Tracer fluid (red circle). It has a size of $90 \mathrm{~mm}$ x $200 \mathrm{~mm}$ 
https://doi.org/10.5194/os-2019-116

Preprint. Discussion started: 2 January 2020

(c) Author(s) 2020. CC BY 4.0 License.

\subsection{System configuration}

The measurement system consists of a combined PIV-LIF camera setup, a double cavity Nd:YAG Laser with a maximum pulse energy of $105 \mathrm{~mJ}$ and a pump system to regulate the inflow of the fluorescence tracer Rhodamine 6G. The laser light sheet is formed by a cylindrical lens from the top side of the water channel through an acrylic glass plate into the water

5 column. The size of the measurement area is confined by the size of the laser light sheet and the field of view of the camera to a maximum of $300 \mathrm{~mm} \times 180 \mathrm{~mm}$. The light sheet is placed in the middle of the water channel directly above the permeable ground model so that the outflow area of the tracer is central in the field of view. The camera system is placed outside of the channel perpendicular to the sheet. The channel has transparent glasses on every side.

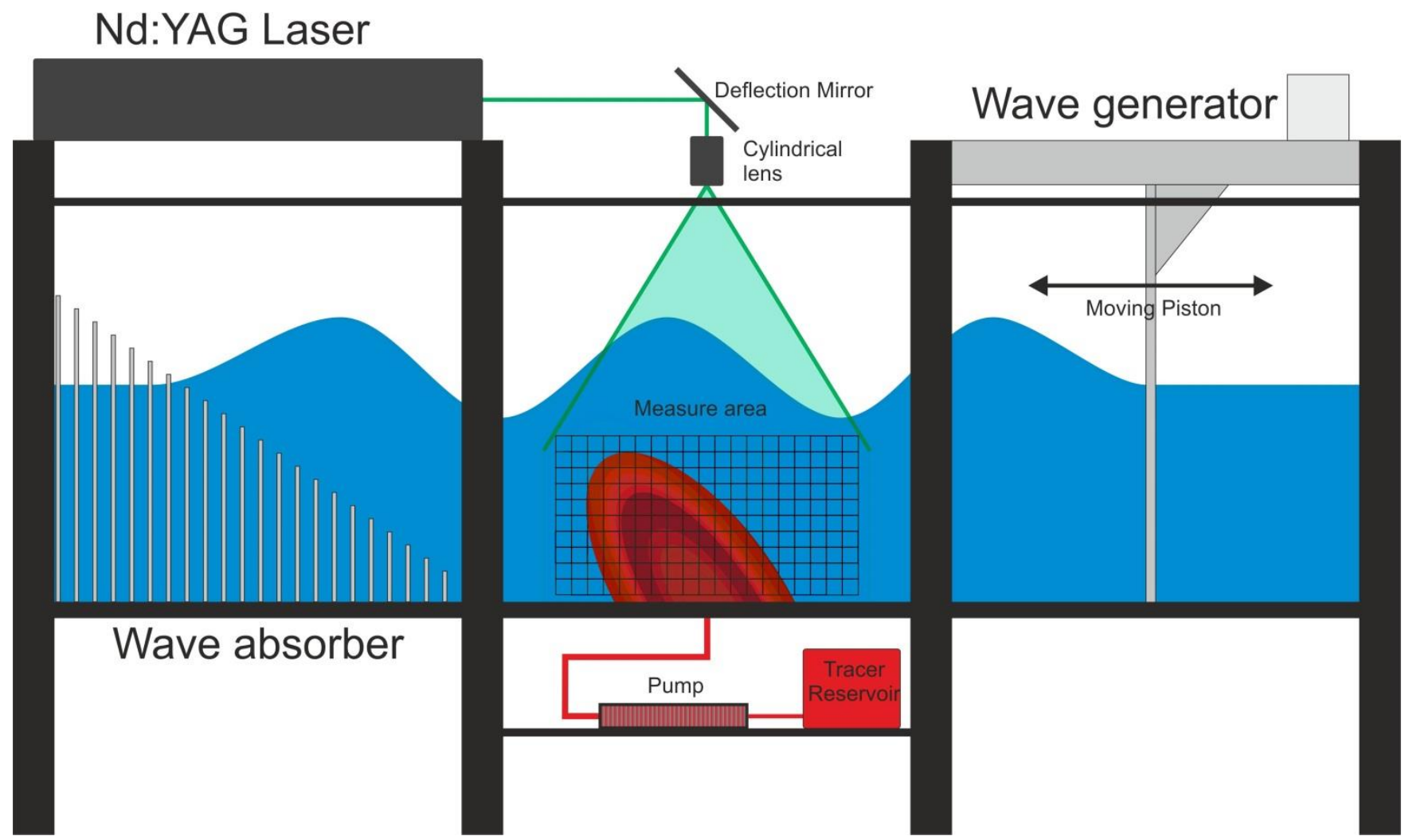

Figure 8: measurement setup

On the left side the plate absorber and on the top the Laser setup. Underneath, the tracer reservoir of the florescent tracer and the pump system. On the right side the piston type wave generator.

15 A constant mass flow of the tracer is delivered by a radial pump placed underneath the water channel. 
https://doi.org/10.5194/os-2019-116

Preprint. Discussion started: 2 January 2020

\subsection{Parameter Setup}

The measurement of the concentration and the velocity field is performed simultaneously employing the PLIF measurement technique. In the measurement area of $269 \mathrm{~mm} \times 149 \mathrm{~mm}$ a double frame rate for PIV/LIF of $7.5 \mathrm{~Hz}$ was chosen. Concerning the sea conditions, the following three wave scenarios have been realized.

Table 1: Characteristics of the wave scenarios used in the water channel experiments

\begin{tabular}{|lccc|}
\hline Scenario & calm & mean \\
scenario & $1,99 \mathrm{~s}$ & $2,52 \mathrm{~s}$ & stormy \\
scenario & scenario \\
\hline Orbital velocity(max) & $0,05 \mathrm{~m} / \mathrm{s}$ & $0,1 \mathrm{~m} / \mathrm{s}$ & $3,3 \mathrm{~s}$ \\
\hline Wave type & intermediate & intermediate & $0,25 \mathrm{~m} / \mathrm{s}$ \\
\hline water depth/wavelength & 0,09 & 0,07 & 0,05 \\
\hline
\end{tabular}

These scenarios are based on field measurement data previously obtained at the reference field study site Hüttelmoor covering approximately half of a year. Two parameters, the wave period and the orbital velocity, were reproduced in the

10 water channel exactly as in nature. Initial experiments have shown, that the wave period and the orbital velocity are the boundary conditions which have the biggest influence on the transport mechanism near the permeable seabed model.

With these wave scenarios and two different permeable seabed models, six measurements were carried out. The permeable seabed model chosen here is a filter medium with a porosity of 10 PPI (pores per inch) and a permeability of 34,7E-10 m². This permeability differs from the values at our field station measurements where permeabilities between 0,04 and 1,13E-10

$15 \mathrm{~m}^{2}$ were found. The increased permeability in our lab experiment, resulting in a time accelerated transport, allowed us to observe the transport processes quantitatively. A second model using a filter medium featuring 45 PPI and 2,35E-10 $\mathrm{m}^{2}$ almost matches the properties of the sea floor at our field station, but the transport could only be observed qualitatively, closely matching the processes observed with the 10 PPI material, but in a slower propagation of the tracer. 


\section{$4 \quad$ Results and Discussion}

For comparison the Reynolds flux model of (Wallis, 1967) is used. The Reynolds fluxes quantify the turbulent effects on the mixing and the transport of scalar quantities. The model is derived from the Reynolds stress approach and is suitable for closure equations in numerical simulations. In this case, the turbulent terms, which usually need additional modelling in the

5 Reynolds averaged Navier-Stokes equations (RANS), are measured as averaged quantities e.g. time averaged $\overline{w^{\prime} c^{\prime}}$, the vertical Reynolds flux.

In the following section, the six measurements are compared on the basis of the vertical Reynolds flux. In Figure 9 the averaged fluxes for the calm scenario with the 10 PPI model and the stormy scenario with the 10 PPI model are plotted.
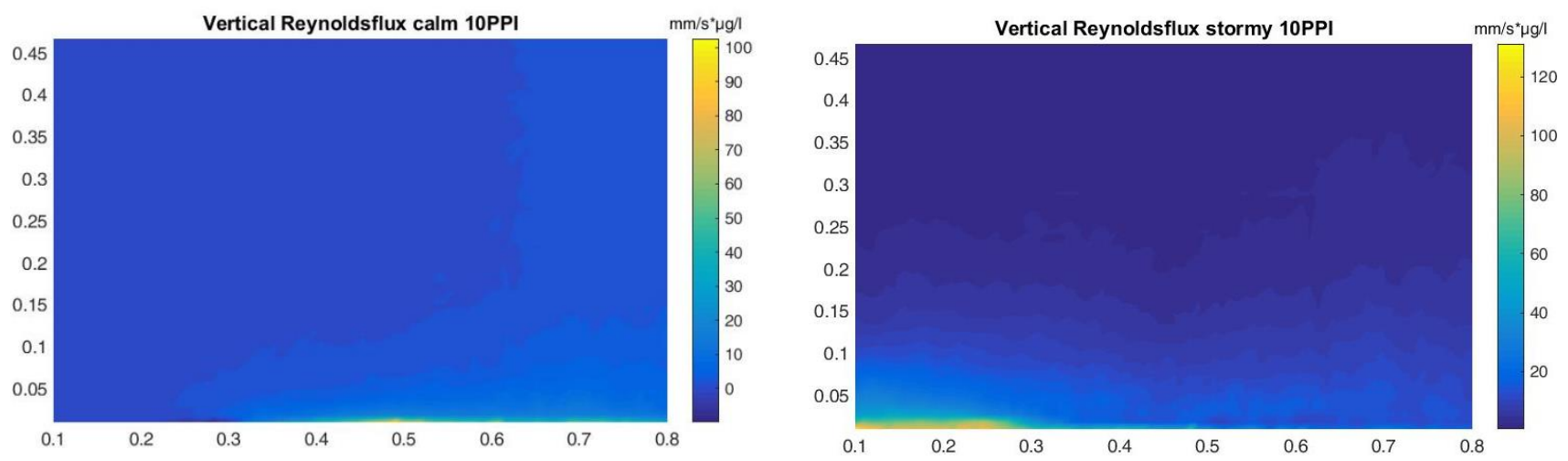

10 Figure 9: vertical Reynolds-flux distribution

On the left side the calm scenario with 10PPI model and on the right side the stormy scenario with the 10 PPI model. The vertical and horizontal axes is normed by the water depth of the experiment.

These distributions of the Reynolds-fluxes represent the most extreme boundary conditions of the experiment. The left side

15 presents the scenario with the calm wave conditions which constitutes the lowest input of wave energy into the measurement area and on the right side presents the stormy wave condition. Hence, the fluxes in the left data set are less intense than those on the right. This clearly demonstrates that the wave action is an important boundary condition for the turbulent transport mechanism. The outflow area of the fluorescence tracer is placed between 0.4 and 0.8 . In case of the calm wave condition only a vertical spread of the tracer directly above the outflow area can be recognized. In contrast the stormy wave action

20 shows a distribution of tracer over the entire ground area and a shift of the point of maximum flux left towards the outflow area. The diffusion into the water column shows in both cases a rapid decrease of the Reynolds-fluxes. For the stormy scenario the gradients of the fluxes are considerably higher than for the calm scenario, due to the higher values of the fluxes. To compare the effects of the wave scenario on the Reynolds-flux, Figure 10 shows the average over the horizontal sampling lines of the mean vertical Reynolds-flux. 


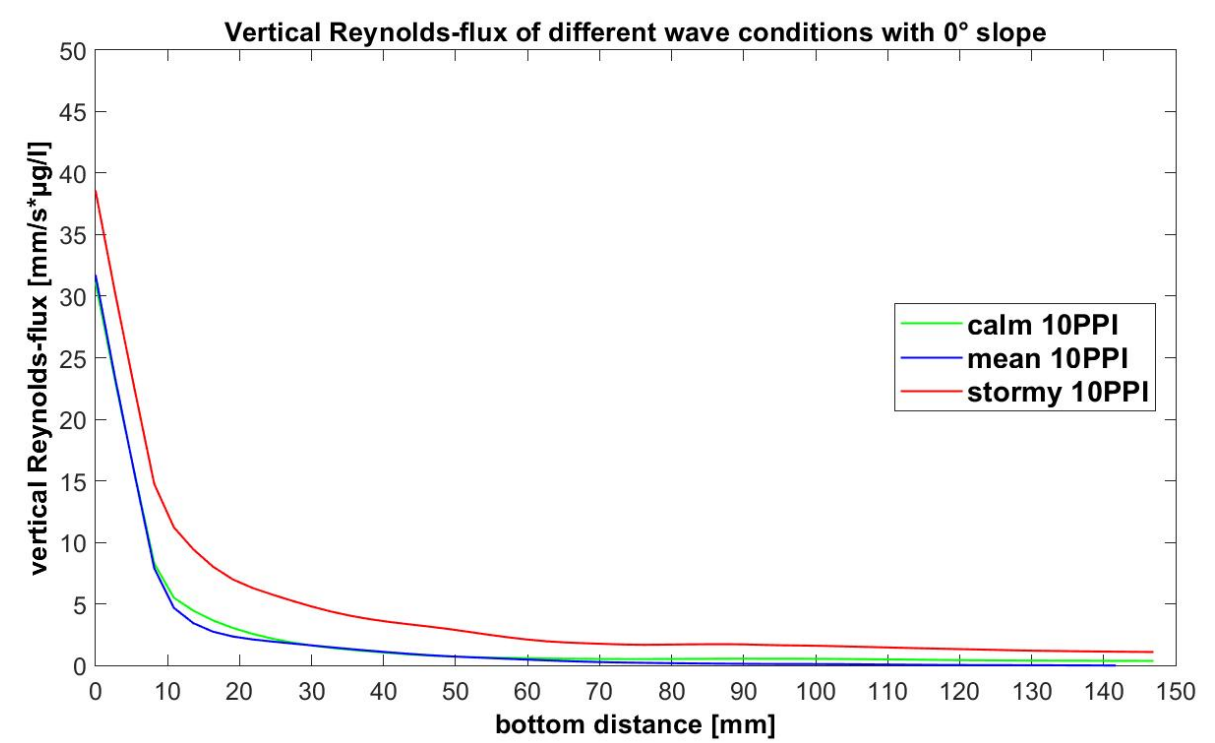

Figure 10: Line Plot of the mean vertical Reynolds-flux

In this figure the averaged Reynolds-fluxes of the experiments with the 10PPI porous medium are shown. The image includes the diffusion for the three wave scenarios calm (green), mean (blue) and stormy (red)

The vertical Reynolds flux is an indicator for the turbulent vertical transport of tracer dye under the wavy conditions during the experiment. The highest rate of turbulent vertical flux is observed near the permeable seabed model. This results from high turbulence values near the ground due to high shear rates at the bottom boundary. Furthermore, the local transport of the tracer dye out of the boundary layer near the surface of the permeable ground model increases with stronger wave action,

10 thus resulting in a larger mixing region whereas the dye remains highly concentrated near the ground and in the seabed for the calm scenario The turbulent mixing of the dye decreases rapidly with higher distance from the ground. Concerning the different wave scenarios, it can be stated that the stormy wave action leads to a larger turbulent mixing zone near the seabed with higher vertical Reynolds fluxes occurring close to the seabed surface. Additionally, the larger flux values spread higher into the overlying water column. As a result, the influence of the tracer to the near environment is much higher compared to

15 the calmer scenarios. The Reynolds-fluxes above the 45PPI ground model show the same development, but with a much lower flux. The decrease of the flux depends on the lower turbulent effect due to the smoother ground model. Hence, the tracer distribution is mostly influenced by the wave action, especially by the wave speed and period. The effect of the seabed properties is also important but has less impact on the shape of the distribution pattern than the wave action.

For numerical simulations it is necessary to use models which can quantitatively describe the turbulent transport phenomena

20 on a subgrid scale. The turbulent transport of a tracer can be described with a scalar transport equation and one of the common solutions is the mixing length model of Prandtl. 
So, additional to the Reynolds fluxes, the mixing lengths of the turbulent diffusion was calculated with the following equation:

$$
\overline{w^{\prime} c^{\prime}}=l_{c}^{2}\left(\frac{\partial \bar{c}}{\partial z}\right)\left|\frac{\partial \bar{u}}{\partial z}\right|
$$

With conversion of Eq. (8) to the mixing length $l_{c}$ the following Figure 11 is plotted for the first $70 \mathrm{~mm}$ of the bottom boundary layer.

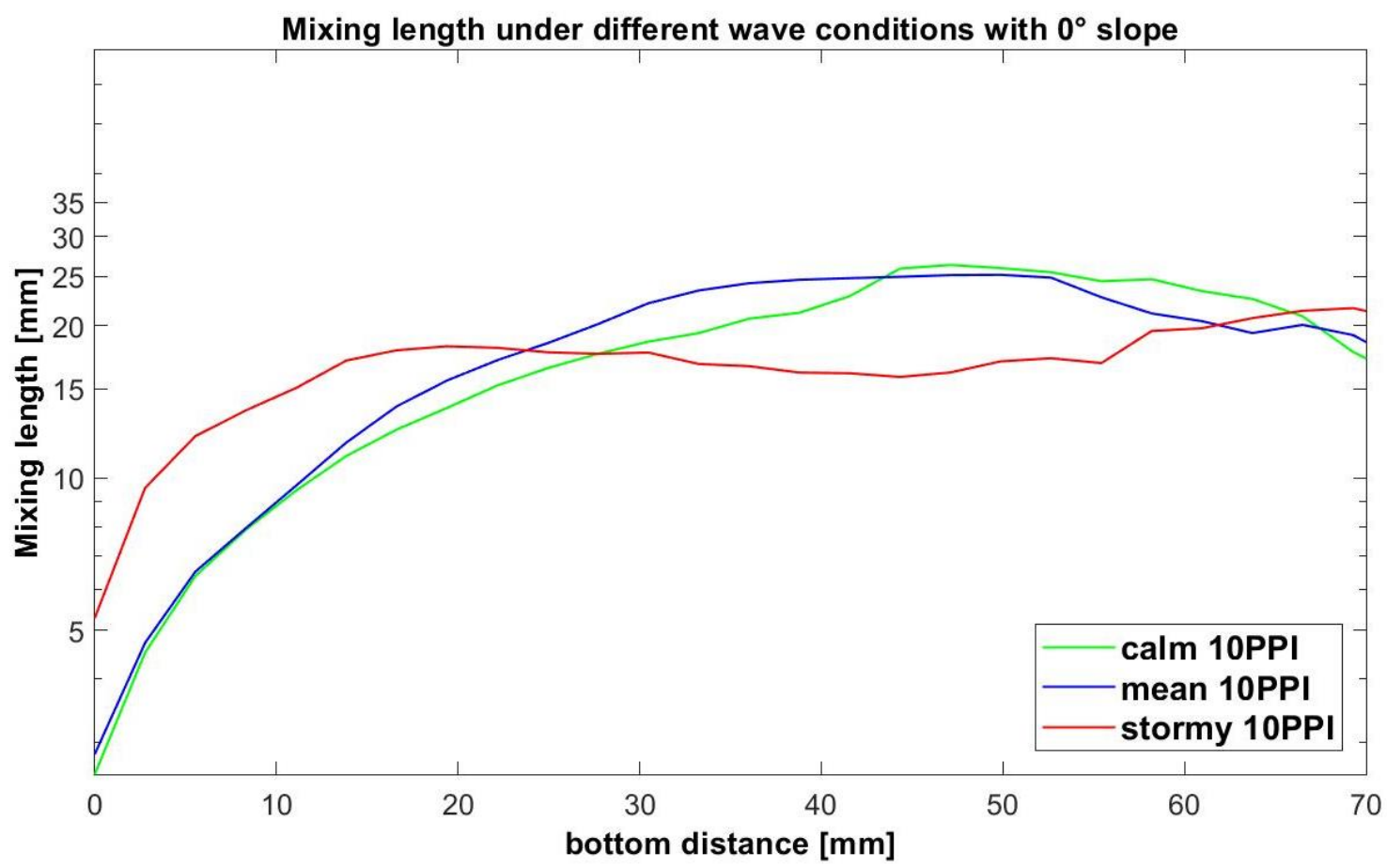

Figure 11: Comparison of the mixing length

In the figure the averaged mixing length of the experiments with the 10PPI porous media are shown. The figure includes the development for the three wave scenarios calm (green), mean (blue) and stormy (red).

10 The mixing length model describes the turbulent motion of a scalar quantity due to turbulent effects. Hence, this figure shows the path for the turbulent movement of a dyed tracer in the experiment. The mixing length is small, if the particle is moving fast within a small area and large, if the particle moves slowly within a big area. Accordingly, the stormy scenario shows a larger mixing length than the calm scenario near the bottom. It can also be obtained from our data, that the mixing length increases with increasing ground distance, approaching an almost constant level for bottom distances larger than

15 approx. 20-30 mm. The square of the mixing length constitutes the proportionality constant between the turbulent Reynolds flux and the gradients of the mean velocity and concentration. Because the velocity and concentration gradients decrease with increasing bottom distance, this leads to the conclusion, that the turbulent mixing motion decreases with increasing 
https://doi.org/10.5194/os-2019-116

Preprint. Discussion started: 2 January 2020

(C) Author(s) 2020. CC BY 4.0 License.

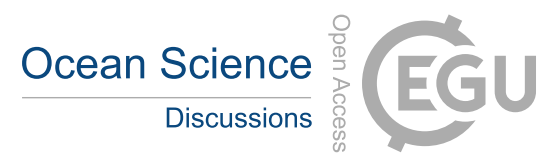

ground distance. This plateau region of the mixing length is bordered by the zone were the tracer dye boundary layer ends.

This results in gradients of the dye fluctuations being nearly zero which constitutes the limit of the mixing length theory. 
https://doi.org/10.5194/os-2019-116

Preprint. Discussion started: 2 January 2020

(c) Author(s) 2020. CC BY 4.0 License.

Comparing the mixing length with the root mean squares of the median of the turbulent kinetic energy leads to the following

\section{Figure 12}

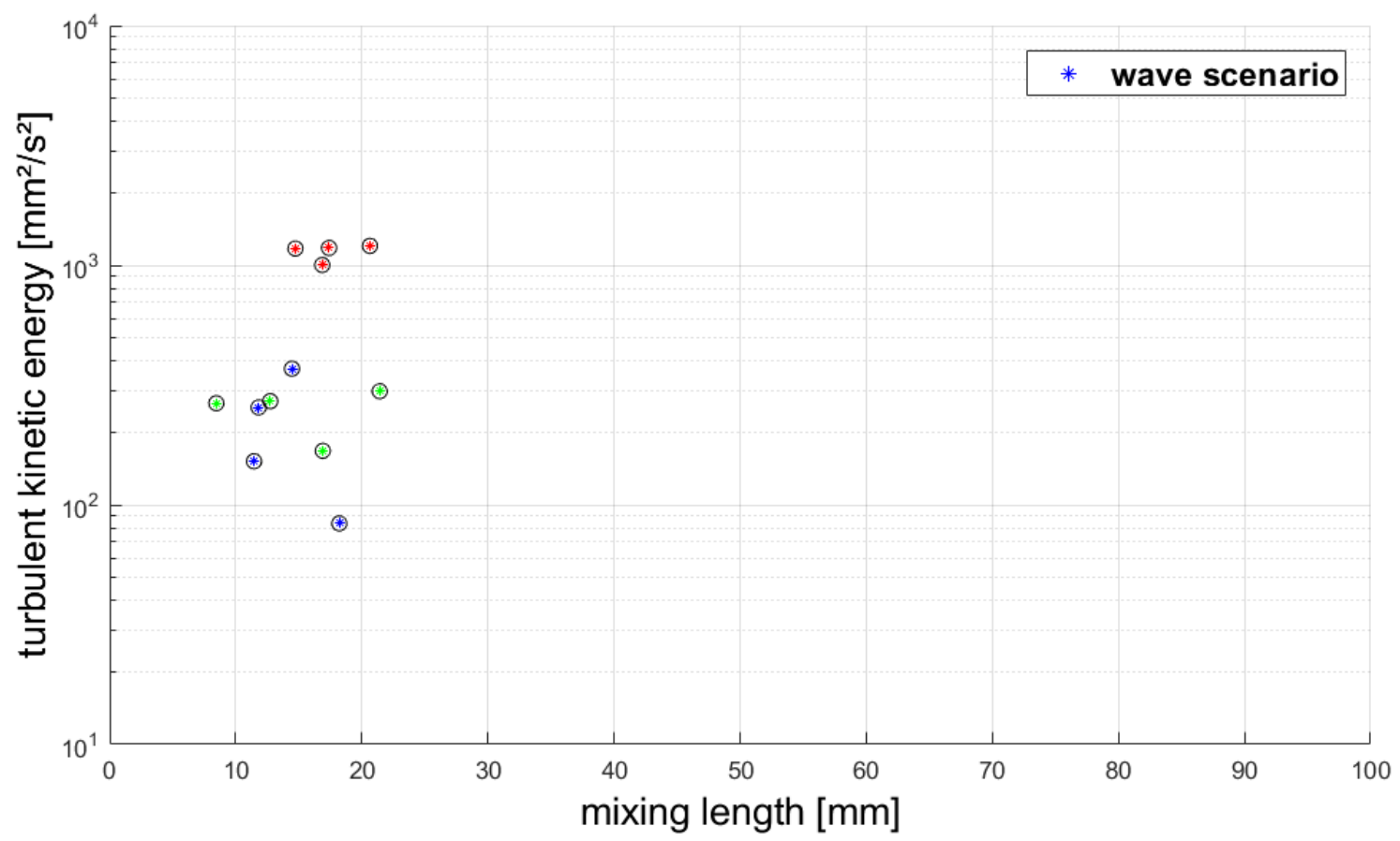

5 Figure 12: Comparison of the mixing length and the Turbulent Kinetic Energy

On the $\mathrm{x}$-axis the mixing length in $\mathrm{mm}$ is shown and, on the $\mathrm{y}$-axis, the turbulent kinetic energy in $\mathrm{mm}^{2} / \mathrm{s}^{2}$ in a logarithmic scale. Furthermore, the wave scenario is marked, for the calm scenario the green star is used, for the mean scenario the blue one and for the stormy scenario the red star is used.

10 Moreover, the colour of the star in the circle denotes the wave scenario, thus the green star stands for the calm scenario, the blue one for the mean scenario and the red one for the stormy scenario. It can be seen, that the mixing length does not correlate with the turbulent kinetic energy level alone. The mixing length during the experiments with the stormy, mean and calm scenario are nearly in the same range. In the calmer scenarios, the turbulent kinetic energy is less than in the stormy scenario because of a lower turbulence. As waves increase, larger velocity and concentration gradients balance the increasing

15 turbulent kinetic energy, so that the mixing length is not altered proportionally. 


\section{Conclusions}

Our PIV-LIF experiments focused on the influence of different wave scenarios and permeability properties of the seabed in the turbulent transport of a tracer. Three different wave conditions derived from field measurement data as well as two different seabed models have been investigated in a wave channel at the Chair of Fluid Mechanics at the University of

5 Rostock. For the quantification of the mixing and dispersion of the tracer from an artificial Submarine Groundwater Discharge (SGD) source in the wave channel, simultaneous Particle Image Velocimetry (PIV) and Laser induced Fluorescence have been used.

The time resolving experiments have resulted in distributions of $\overline{w^{\prime} c^{\prime}}$ as well as distributions of time averaged velocities and

10 concentrations. Using this data, the concentration boundary layer could be characterized, and time average values of the Reynolds-fluxes were determined. To support further modelling on the SGD transport in the otherwise unresolved bottom boundary layer, the transport coefficient from Prandtl's Mixing Length Theory was derived from the experimental results. The results show that the Reynolds-fluxes as well as the mixing length indicate a clear dependence on the distance above the ground. While the Reynolds-fluxes show the highest values near the ground and decrease asymptotically to zero with

15 increasing distance, the mixing length increases with increasing bottom distance.

With respect to the influence of the wave scenario settings we can conclude, that the Reynolds-fluxes are highest for the storm scenario and lowest for the calm scenario. Compared to the other two, the storm scenarios additionally lead to a larger zone of high Reynolds-flux, up to a bottom distance of $40 \mathrm{~mm}$ for a $90 \%$ decrease from the value at the bottom.

20 Accordingly, the mixing length is the largest for the storm scenario indicating a dominance of larger scale structures with lower gradients.

From the experimental data the mixing length was calculated depending on the bottom distance (see Figure 12). This parameter converges to an almost constant value, with the coordinate of the beginning of this plateau being different for the different wave scenarios, whereas the size of the mixing lenth remains largely independent of the scenario. The resulting

25 values and the near bottom profile of the mixing length can now be used to model the turbulent transport from a calculated average velocity and concentration field in greater detail in an advanced numerical simulation..

The simultaneous usage of the PIV and the LIF has shown, that these measurement techniques are predestined to measure the distribution and mixing of a tracer dye under different wave action.

30 In further experiments a smaller measurement area will allow a more detailed view on the smaller scales of the mechanisms. Furthermore, the slope angle will be varied. Moreover, a defined bottom structures will be investigated like a defined ripple structure. 
https://doi.org/10.5194/os-2019-116

Preprint. Discussion started: 2 January 2020

(C) Author(s) 2020. CC BY 4.0 License.

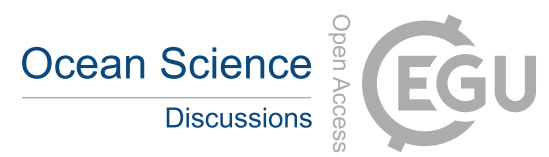

\section{Acknowledgements}

The research was founded by the German Science Foundation (Deutsche Forschungsgemeinschaft DFG) in the graduate school "Baltic Transcoast" project P4 ("Waves and turbulence on wavy coastal seabeds inducing vertical scalar transport"). 
https://doi.org/10.5194/os-2019-116

Preprint. Discussion started: 2 January 2020

\section{$7 \quad$ References}

Airy, G. B.: On tides and waves, Encylopaedia Metropolitana, London, 1845.

Ausschuß für Küstenschutzwerke: EAK 2002: Empfehlungen für die Ausführung von Küstenschutzwerken, Die Küste, 65.2002, Westholsteinische Verl.-Anst. Boyens, Heide, 589 pp., 2002.

Boudreau, B. P. and Jørgensen, B. B. (Eds.): The benthic boundary layer: Transport processes and biogeochemistry, Oxford Univ. Press, Oxford, 404 pp., 2001.

Burnett, W. C., Aggarwal, P. K., Aureli, A., Bokuniewicz, H., Cable, J. E., Charette, M. A., Kontar, E., Krupa, S., Kulkarni, K. M., Loveless, A., Moore, W. S., Oberdorfer, J. A., Oliveira, J., Ozyurt, N., Povinec, P., Privitera, A. M. G., Rajar, R., Ramessur, R. T., Scholten, J., Stieglitz, T., Taniguchi, M., and Turner, J. V.: Quantifying submarine groundwater discharge in the coastal zone via multiple methods, The Science of the total environment, 367, 498-543, https://doi.org/10.1016/j.scitotenv.2006.05.009, 2006.

Burnett, W. C., Taniguchi, M., and Oberdorfer, J.: Measurement and significance of the direct discharge of groundwater into the coastal zone, Jounar of Sea Research, 109-116, 2001.

Feddersen, F.: Observations of the Surf-Zone Turbulent Dissipation Rate, J. Phys. Oceanogr., 42, 386-399, https://doi.org/10.1175/JPO-D-11-082.1, 2012.

Finkl, C. W. and Krupa, S.: Environmental Impacts of Coastal-Plain Activities on Sandy Beach Systems: Hazards, Perception and Mitigation, Journal of Coastal Research, 35, 132-150, 2003.

Huettel, M., Ziebis, W., and Forster, S.: Flow-induced uptake of particulate matter in permeable sediments, Limnology and Oceanography, 41, 309-322, 1996.

IOC, SCOR, IAEA, and Poland, J. F.: Submarine groundwater discharge // Guidebook to studies of land subsidence due to ground-water withdrawal: Management implications, measurements and effects, Series on groundwater / IHP-VI, 5 // 40, UNESCO, Paris, 35 pp., 2004 // 1984.

Leote, C., Ibánhez, J. S., and Rocha, C.: Submarine Groundwater Discharge as a nitrogen source to the Ria Formosa studied with seepage meters, Biogeochemistry, 88, 185-194, https://doi.org/10.1007/s10533-008-9204-9, 2008.

Matthäus, W. and Franck, H.: Characteristics of major Baltic inflows: A statistical analysis, Continental shelf res., 1375$1400,1992$.

Miegel, K., Thomas Graeff, Benny Selle, Thomas Salzmann, Christian Franck, and Axel Bronstert: Untersuchung eines renaturierten Niedermoores an der mecklenburgischen Ostseeküste - Teil I: Systembeschreibung und hydrologische Grundcharakterisierung, Hydrologie und Wasserbewirtschaftung/ BfG, 60, 242-258, https://doi.org/10.5675/HyWa_2016,4_1, 2016.

Moore, W. S.: The effect of submarine groundwater discharge on the ocean, Annual review of marine science, 2, 59-88, https://doi.org/10.1146/annurev-marine-120308-081019, 2010. 
https://doi.org/10.5194/os-2019-116

Preprint. Discussion started: 2 January 2020

(c) Author(s) 2020. CC BY 4.0 License.

Discussions

(c) (P)

Precht, E. and Huettel, M.: Advective pore-water exchange driven by surface gravity waves and its ecological implications, Limnology and Oceanography, 48, 1674-1684, 2003.

Robinson, C., Li, L., and Barry, D. A.: Effect of tidal forcing on a subterranean estuary, Advances in Water Resources, 30, 851-865, https://doi.org/10.1016/j.advwatres.2006.07.006, 2007.

5 Schlichting, H.: Grenzschicht-Theorie, 2., unveränd. Aufl., Wissenschaftliche Bücherei, Braun, Karlsruhe, 483 pp., 1954.

Stokes, G. G. (Ed.): Mathematical and physical papers: Volume 1, Cambridge library collection. Mathematics, Cambridge University Press, Cambridge, 328 pp., 2009.

Taniguchi, M., Ishitobi, T., and Shimada, J.: Dynamics of submarine groundwater discharge and freshwater-seawater interface, J. Geophys. Res., 111, https://doi.org/10.1029/2005JC002924, 2006.

10 Ullman, W. J., Chang, B., Miller, D. C., and Madsen, J. A.: Groundwater mixing, nutrient diagenesis, and discharges across a sandy beachface, Cape Henlopen, Delaware (USA), Estuarine, Coastal and Shelf Science, 57, 539-552, https://doi.org/10.1016/S0272-7714(02)00398-0, 2003.

Wallis, G. B.: Use of the Reynolds Flux Concept for Analysing One-Dimensional Two-Phase Flow: Part 1. Derivation and Verification of Basic Analytical Techniques, Intenational Journal Heat Mass Transfer, 11, 445-458, 1967. 